\title{
Depression Among the University Students in Arghakhanchi District
}

\author{
Durga Khadka Mishra, Rajan Bhusal*, Ridesh Pokharel, Shreesti Sharma
}

Department of Public Health, Manmohan Memorial Institute of Health Sciences, Kathamnadu, Nepal

\author{
Email address: \\ Bhusalrajann55@gmail.com (R. Bhusal) \\ ${ }^{*}$ Corresponding author
}

\section{To cite this article:}

Durga Khadka Mishra, Rajan Bhusal, Ridesh Pokharel, Shreesti Sharma. Depression Among the University Students in Arghakhanchi District. American Journal of Applied Psychology. Vol. 10, No. 4, 2021, pp. 95-100. doi: 10.11648/j.ajap.20211004.12

Received: July 29, 2021; Accepted: August 12, 2021; Published: August 31, 2021

\begin{abstract}
A Depression is one of the major mental illnesses of today's generation and is a common mental disorder. Depression is characterized by a loss of interest and a persistent sadness in activities that people usually enjoy, associated with an inability to carry out daily activities, for at least two weeks. Also, people with depression typically have several of the following a change in appetite; loss of energy; anxiety; sleeping more or less; reduced concentration; indecisiveness; restlessness; feelings of worthlessness, guilt, or hopelessness; along with thoughts of self-harm or suicide. Depression is treatable, with cognitive therapies or antidepressant medication or a combination of these. The descriptive cross-sectional study was carried out to assess the level of depression among university students of Arghakhanchi district. The self-administered, pre-tested questionnaire, including the Beck Depression Inventory (BDI), was used to collect information on demographics, personal and academic factors, and depression level. Informed written consent was taken with a questionnaire. Collected data from university students were entered and analysed using (SPSS) software version 25. Chi-square test was used in this research to find out the association between the variables. Out of the total students, $40.6 \%$ of students were suffering from mild to the extremely severe level of depression, and remaining $59.4 \%$ of the students were normal. Results shows statistically significant association between age $\&$ depression $(p=0.005)$, ethnicity \& depression $(p=0.0035)$ and faculty of study and depression $(p=0.003)$. The high prevalence of depression among university students is an alarming figure that needs urgent attention and warrants towards strategic planning with the need for primary and secondary prevention measures.
\end{abstract}

Keywords: Depression, University Students, Arghakhanchi, Management, Education

\section{Introduction}

Mental health is an essential and integral important component of health. The WHO constitution states, "Health is a state of complete physical, mental and social well-being and not merely the absence of disease or infirmity." The critical implication of this definition is that mental health is more than just the absence of mental disorders or disabilities. [1] It is a condition of prosperity where in an individual understands his or her capacities, whom he can adjust to the run of the mill stresses of life and can add to his or her locale by working gainfully [1].

A Depression is one of the major mental illnesses of today's generation and is a common mental disorder. It is characterized by a loss of interest and a persistent sadness in activities that people usually enjoy, associated with an inability to carry out daily activities, for at least two weeks [2]. Also, people with depression typically have several of the following a change in appetite; loss of energy; anxiety; sleeping more or less; indecisiveness; restlessness; reduced concentration, guilt, feelings of worthlessness or hopelessness; and thoughts of self-harm or suicide. Depression is treatable, with cognitive therapies or antidepressant medication or a combination of these [2].

Depression among university students is a widespread problem across the country. University students are a group of people that are going through a short period in which they are going from adolescence to adulthood. it can be one of the most stressful times in a person's life. Endeavoring to fit in, plan for the future, keep up decent evaluations, and being far from home frequently causes tension for a ton of understudies. As a response to this circumstance, a few 
understudies get discouraged in reacting to the situation. They find that they cannot get themselves together. They may continuously cry, skip classes, or disconnect themselves without acknowledging; they are depressed [3].

Depression is a common illness worldwide; it affects 300 million people. It is different from short-lived emotional responses to challenges in everyday life and frequent mood fluctuations and especially when it is long-lasting, and with moderate or severe intensity, depression may become a critical health condition. It affects a person to suffer much and function poorly at school, at work, and also within the family. At its worst, it pushes a person to commit suicide. Somewhere close to 800000 people die by committing suicide every year. Suicide ranks second leading cause in death in 15-29-year-olds [1].

World Health Organization (WHO) has estimated that 26\% of the world's population of the WHO South-East Asia Regions 11 countries, which accounts for 39\% of global death due to suicides. Suicide is estimated to have contributed in 800000 deaths worldwide in 2012, representing an annual global age-stata [4].

The standardised suicide rate, which accounts 11.4 per 100 000 , the second- leading cause of death among 15-29-year old's and a 15th-most common cause of death worldwide [5].

A study conducted among Kathmandu University Medical School (KUSMS), Dhulikhel and Manipal College of Medical Sciences (MCOMS), Pokhara, Nepal showed a higher level of psychiatric morbidity depression 29.9\%, anxiety $41.1 \%$ and stress $27 \%$ among undergraduate medical students [6].

A study conducted on 252 students in 4th-year MBBS to 1st-year MBBS. Of these, 189 were present during the survey. Using anxiety and depression scale, it was found out that $113(60 \%)$ students had anxiety and depression [7].

The other study conducted in Nepal to find out Anxiety and depression in Nepal prevalence, comorbidity, and associations. The total sample included 2100 participants (males 861 [41.0\%], females 1239 [59.0\%], mean age $36.4 \pm$ 12.8 years). The participation rate was $99.6 \%$. There was no missing data. prevalence of anxiety $22.7 \%$ and depression $11.7 \%$. The age- and gender-adjusted prevalence of HADS-A was $16.1 \%$, of HADS-D $4.2 \%$ and HADS-cAD 5.9\% [8].

A cross-sectional descriptive correlational study on prevalence and socio-demographic correlates of depressive symptoms among Cypriot universe s its students shows that Greek (32.8\%) were more depressed then Cypriot (27.6\%) based on ethnicity [9].

\section{Methods}

\subsection{Study Design, Setting and Participants}

The descriptive cross-sectional study was carried out to assess the level of depression among university students in Arghakhanchi districts from April 14, 2018, to July 15, 2018. The study site for conduction of the research colleges affiliated to Tribhuwan University in Arghakhanchi district,
Nepal. The study populations were the students from management and education faculties of the colleges in the Arghakhanchi district. Study unit taken was Individual students.

\subsection{Data Collection Techniques}

By using self-administered questionnaire tools, Structured questionnaire was used for collecting general information on various factors and standard BDI questionnaire tool to access the level of the depression, and data were collected.

Table 1. Interpretation of the Beck depression inventory tool (Fallis, 2013).

\begin{tabular}{ll}
\hline Total Score & Levels of Depression \\
\hline $1-10$ & these ups and downs are considered normal \\
$11-16$ & Mild mood disturbance \\
$17-20$ & Borderline clinical depression \\
$21-30$ & Moderate depression \\
$31-40$ & severe depression \\
Over 40 & Extreme depression \\
\hline
\end{tabular}

The above Table 1 shows the interpretation of the Beck Depression Inventory tools, ranging from 1 to over 40 and subsequent interpretation.

\subsection{Pre-testing of Data Collection}

The study instrument was pre-tested to identify the consistency of the tools at Sandhikharka Municipality among the university students, and there was no change in the questionnaire after the pre-testing.

\subsection{Operational Definitions}

Depression- Depression is a common mental disorder, characterised by persistent sadness and a loss of interest in activities that you normally enjoy, accompanied by an inability to carry out daily activities, for at least two weeks [2].

University students - In this study, university students are defined as those who are studying management and Education courses.

The course of study: Faculty of students was categorized into management and education.

Year of study: Year in which the students were studying was categorized as $1^{\text {st }}$ and $2^{\text {nd }}$ year.

The education level of parents: Education of parents was categorized into two as father's education level and mother's education level. Education level was classified as Illiterate, Literate, Basic (1-8 grade), Secondary (9-12) and University level. In this study, illiterate were individuals who were not able to read and write, and literate were those individuals who could read and write.

Monthly income of a family: Monthly income was categorized as <NRs.25000, NRs.25000-40000 and $>$ Nrs.40000 and in close range to the Government of Nepal health cadres' salary. 


\subsection{Sample Size}

The simple random sampling method of sampling was carried out in selecting the colleges, and among them, Probability Proportionate Sampling (PPS) was further done, and after getting the total number of students from colleges, the number of students was divided proportionately according to the number of students in the respective colleges.

A required sample size of the study was calculated using the formula for the population at large developed by Cochran in 1963 which is

$$
\mathrm{n}=\left(\mathrm{Z}^{2} \mathrm{pq}\right) / \mathrm{d}^{2}
$$

Where,

$\mathrm{N}=800$ (total university students in Arghakhanchi districts)

$\mathrm{n}=$ desired sample size

$\mathrm{Z}=$ standard normal deviate, usually set at 1.96 which correspond to $95 \%$ confidence level

$\mathrm{p}=$ proportion in the target population estimated to have a particular characteristic $(P=11.7 \%$, A Study conducted on Anxiety and depression in Nepal prevalence, comorbidity, and association [8]

$\mathrm{d}=$ degree of accuracy required, usually set at 0.05 level

Therefore, $n=\left(Z^{2} p q\right) / d^{2}$

$$
\begin{aligned}
& =(1.96)^{2} * 0.117 * 0.883 /(0.05) \wedge 2 \\
= & 159
\end{aligned}
$$

Taking $10 \%$ of the sample size as the non-response rate, the final sample size was;

$$
\begin{aligned}
& =159+10 \% \text { of } 159 \\
& =175
\end{aligned}
$$

\subsection{Ethical Consideration}

Ethical approval was taken from the Institutional Review Committee (IRC) of Manmohan Memorial Institute of Health Sciences. The participants were informed and counselled about aims, methods, and anticipated benefits and of the s/study program. Written and verbal informed consent was taken with every respondent. Neither pressure nor inducement was done to encourage any person to participate in the study. During the study period, all the ethical consideration, as well as confidentiality, was maintained to respect for human dignity and principle of justice.

\subsection{Data Management and Analysis}

The data was entered, coded, analysed, and interpreted according to the objective of the study using SPSSv25.0 software, MS Excel.

\section{Results}

A total of 175 (i.e., 83 Management students and 92 education students) filled and returned the questionnaire. The overall response rate was $100 \%$. The results were interpreted in the 175-sample population of management and education students. Data were analysed based on the demographics, socioeconomic, academic, and other factors.

\subsection{Statistical Analysis}

\subsubsection{Demographic Factors}

Table 2. Demographic characteristics of the respondents.

\begin{tabular}{lll}
\hline Factors & Number & Percentage (\%) \\
\hline Age & 165 & \\
$18-20$ & 10 & 94.3 \\
$21-26$ & & 5.7 \\
Gender & 43 & \\
Male & 132 & 24.6 \\
Female & & 75.4 \\
Religion & 175 & \\
Hindu & & 100 \\
Ethnicity & 128 & \\
Brahmin/Chhetri & 34 & 73.1 \\
Janajati & 13 & 19.4 \\
Dalit & & 7.4 \\
\hline
\end{tabular}

The above table 2 shows the respondents' ages categorized into 18-20 years of age and 21-26 years of age with respondents of age 18-20 years of age being the majority population (94.3\%). Hindu religion was the dominant one with the majority $(100 \%)$ of the population following the Hindu religion. Brahmin/Chhetri was the dominant ethnic group, with $73.1 \%$ of the total population, followed by Janajati, representing $19.4 \%$ of the total population.

\subsubsection{Academic Findings}

Table 3. Academic characteristics of the respondents.

\begin{tabular}{lll}
\hline Factors & Numbers & Percentage\% \\
\hline Faculty of study & & \\
Management & 83 & 47.4 \\
Education & 92 & 52.6 \\
Year of study & & \\
Bachelor 1st year & 126 & 72 \\
Bachelor 2nd year & 49 & 28 \\
\hline
\end{tabular}

The above table 3 shows academic findings, there were 83 management's students which consist of $47.4 \%$ of the sample population and on education faculty, there were 92 students which comprised of $52.6 \%$ of the sample population. We took the bachelor $1^{\text {st }}$ and $2^{\text {nd }}$-year student's $1^{\text {st }}$ - year students include $72 \%$, and bachelor $2^{\text {nd }}$-year students include $28 \%$ of the 175 -sample population.

\subsubsection{Socioeconomic Findings}

Table 4. Socioeconomic findings of the respondents.

\begin{tabular}{lll}
\hline Factors & Numbers & Percentage\% \\
\hline Education of the father & & \\
Illiterate & 27 & 15.4 \\
Literate & 15 & 8.6 \\
\hline
\end{tabular}




\begin{tabular}{|c|c|c|c|}
\hline Factors & & Numbers & Percentage\% \\
\hline Basic (1-8) & & 66 & 37.7 \\
\hline Secondary (9-12) & & 52 & 29.7 \\
\hline University & & 15 & 8.6 \\
\hline \multicolumn{4}{|c|}{ Education of mother } \\
\hline Illiterate & & 36 & 8.4 \\
\hline Literate & & 25 & 15.6 \\
\hline Basic (1-8) & & 72 & 12.4 \\
\hline Secondary (9-12) & & 42 & 33.2 \\
\hline $\begin{array}{l}\text { Monthly } \\
\text { family (NRs) }\end{array}$ & income & of a & \\
\hline$<25000$ & & 132 & 75.4 \\
\hline $25000-40000$ & & 30 & 17.1 \\
\hline$>40000$ & & 13 & 13 \\
\hline Financial & support & From & \\
\hline \multicolumn{4}{|l|}{ Parents } \\
\hline Yes & & 168 & 96 \\
\hline No & & 7 & 4 \\
\hline
\end{tabular}

Above the table 4 shows the findings on the socioeconomic factors. Fathers who received a primary education $(37.7 \%)$ were in a more significant proportion. The majority $(33.2 \%)$ of the mothers received a high school education. Monthly income of the family was categorized into three groups, with $75.4 \%$ family having monthly income NRs. $<25000$ followed by a family having NRs.25000-40000 (17.1\%) and NRs. $>40000$ $(13 \%)$ as a monthly income. Most $(96 \%)$ of the students received financial support from parents.

\subsubsection{Other Factors $(n=175)$}

The Family history of the mental illness was found to be in $4.6 \%$ of the students. Personal history of the mental illness is found to be in very few populations, i.e., $1.1 \%$ and no one found to have the family history of the suicide attempt, personal history of the suicide attempt and no one found to be smoking and consumption of the alcohol.
Table 5. Other findings of the respondents.

\begin{tabular}{lll}
\hline Factors & Numbers & Percentages\% \\
\hline Family history of the mental illness & & \\
Yes & 8 & 4.6 \\
No & 167 & 95.4 \\
$\begin{array}{l}\text { Personal history of mental illness } \\
\text { Yes }\end{array}$ & 2 & 1.1 \\
No & 173 & 98.1 \\
Family history of suicide attempt & & \\
No & 175 & 100 \\
Personal history of suicide attempt & & \\
$\begin{array}{l}\text { No } \\
\text { Consumption of alcohol }\end{array}$ & 175 & 100 \\
No & 175 & 100 \\
Smoking & & \\
No & 175 & 100 \\
\hline
\end{tabular}

\subsection{Level of Depression Among University Students}

Table 6. Level of the Depression Among University Students.

\begin{tabular}{lll}
\hline Level & Frequency & Percentage \\
\hline Normal & 104 & $59.4 \%$ \\
Mild & 18 & $10.3 \%$ \\
Borderline clinical & & \\
depression & 26 & $14.9 \%$ \\
Moderate & 23 & $13.1 \%$ \\
Severe depression & 4 & $2.3 \%$ \\
Total & 175 & $100 \%$ \\
\hline
\end{tabular}

The above table 6 depicts the level of depression, which was categorized as normal, mild, moderate, severe, and extremely severe. The students with depression level from mild to extremely severe were the ones suffering from depression. Of the total students, $40.6 \%$ of students were suffering from mild to extremely severe level of depression, and remaining $59.4 \%$ of the students were normal.

\subsection{Factors Associated with Depression}

Table 7. Factors associated with Depression

\begin{tabular}{|c|c|c|c|c|c|}
\hline Factors & Depression $($ Yes $=71)$ & Depression $(\mathrm{No}=104)$ & Odds Ratio OR & $95 \% \mathrm{CI}$ & p-value \\
\hline \multicolumn{6}{|l|}{ Age } \\
\hline $18-20$ & 64 & 101 & 0.272 & \multirow{2}{*}{$0.068-1.088$} & \multirow{2}{*}{0.05} \\
\hline $21-26$ & 7 & 3 & 1 & & \\
\hline \multicolumn{6}{|l|}{ Gender } \\
\hline Male & 18 & 53 & 1.073 & \multirow{2}{*}{$0.534-2.158$} & \multirow{2}{*}{0.843} \\
\hline Female & 25 & 79 & 1 & & \\
\hline \multicolumn{6}{|l|}{ Ethnicity } \\
\hline Brahmin/Chhetri & 58 & 13 & 2.167 & \multirow{2}{*}{$1.047-4.487$} & \multirow{2}{*}{0.0035} \\
\hline Non-Brahmin/Chhetri & 70 & 34 & 1 & & \\
\hline \multicolumn{6}{|l|}{ Faculty } \\
\hline Management & 24 & 59 & 0.389 & \multirow{2}{*}{$0.208-0.729$} & \multirow{2}{*}{0.003} \\
\hline Education & 47 & 45 & 1 & & \\
\hline \multicolumn{6}{|l|}{ Year of study } \\
\hline $1^{\text {st }}$ year & 49 & 77 & 0.781 & \multirow{2}{*}{$0.401-1.522$} & \multirow{2}{*}{0.467} \\
\hline $2^{\text {nd }}$ year & 22 & 27 & 1 & & \\
\hline \multicolumn{6}{|l|}{ Education of father } \\
\hline Illiterate & 10 & 17 & 0.839 & \multirow{2}{*}{$0.360-1.957$} & \multirow{2}{*}{0.684} \\
\hline Literate & 61 & 87 & 1 & & \\
\hline \multicolumn{6}{|l|}{ Education of mother } \\
\hline Illiterate & 14 & 22 & 0.915 & \multirow{2}{*}{$0.432-1.939$} & \multirow{2}{*}{0.818} \\
\hline Literate & 57 & 82 & 1 & & \\
\hline
\end{tabular}




\begin{tabular}{|c|c|c|c|c|c|}
\hline Factors & Depression $($ Yes=71) & Depression $(\mathrm{No}=104)$ & Odds Ratio OR & $95 \%$ CI & p-value \\
\hline \multicolumn{6}{|c|}{ Family income } \\
\hline$<25000$ & 57 & 75 & 1.574 & \multirow{2}{*}{$0.763-3.250$} & \multirow{2}{*}{0.218} \\
\hline$>25000$ & 14 & 29 & 1 & & \\
\hline \multicolumn{6}{|c|}{ Personal history of mental illness } \\
\hline Yes & 2 & 69 & 0.972 & \multirow{2}{*}{$0.934-1.011$} & \multirow{2}{*}{0.85} \\
\hline No & 0 & 104 & 1 & & \\
\hline
\end{tabular}

The above table 7 depicts the factors associated with depression. Data shows statistically significant association between age and depression $(\mathrm{p}=0.005)$. Though there was no significant association between gender and depression similarly, there was a significant difference between ethnicity and depression $(\mathrm{p}=0.0035)$ Brahmin and Chhetri are 2.167 times more likely to be depressed then non-Brahmin/Chhetri $(\mathrm{OR}=2.167, \mathrm{CI}=1.047-4.487)$.

Research shows a statistically significant difference between faculty of study and depression $(p=0.003)$; management students are more prone to be depressed than the education students $(\mathrm{OR}=0.389, \mathrm{CI}=0.208-0.729)$. There was no significant association between the $1^{\text {st }}$ year students and $2^{\text {nd }}$ year students; likewise, there found to have no significant difference between the education of father and depression and there perceived to be no significant differences between the personal history of mental illness and depression.

\section{Discussion}

As per the study, depression in university students was analyzed, and their associations with various factors were studied. Prevalence of depression found to be $40.6 \%$ from mild to the severe was found. A previous study found that the prevalence of depression among medical students was $29.2 \%$ (95\% CI, 24.4\% - 34.3\%) [10]. Prevalence of depression is found to be more in our study, which may be due to different settings. In sample size and different target population than the study on depression or depressive symptom in which prevalence data were extracted from 167 cross-sectional studies $(\mathrm{n}=116628)$ and 16 longitudinal studies $(\mathrm{n}=5728)$ from data of 43 countries. The study found overall pooled prevalence (crude) of depression or depressive symptoms was $27.2 \%$ seen in the research called Prevalence of Depression, Depressive Symptoms, and Suicidal Ideation Among Medical Students [11].

In our study, age is found to be significantly associated with the depression $(\mathrm{p}=0.005)$ which is also supported by a study on Prevalence of Anxiety and Depression among Medical Students; where age is found to be associated with the Depression $(\mathrm{p}=0.004)$ [12].

Our findings show that students having poor socioeconomic status are more likely to be depressed which is also supported by the study on the Malaysia where the prevalence of moderate to extremely severe level of depression among undergraduate students in Malaysia was ranging from $13.9 \%$ to $29.3 \%$ in this study there found to be an association between social life and depression, and lower socioeconomic status is strongly associated with major depressive disorder and Students with lower total family income per month may encounter problem with every day's expenses and thus contributing to the precipitating factors for depression [13].

Our study also shows that the female is more likely to be depressed which is also found similar on the study of the prevalence of poor mental health among medical students in Nepal A cross-sectional research shows that the prevalence of depression was found to be $29.2 \%$. the study indicates that the Females were more likely to have medium to highly severe somatic symptoms and depression in the context of Year in medical school Prevalence of depression was significantly higher in pre-clinical students [10].

A study conducted on Depressive symptomatology among university students in Denizli, Turkey prevalence and sociodemographic correlates show Out of all participants, $26.2 \%$ had a BDI score of 17 or higher. Prevalence of depressive symptoms increased to $34.7 \%$ among students with low socioeconomic status, $32.1 \%$ among older students, $31.2 \%$ among seniors, and $62.9 \%$ amongstudentswith poor school performance. There found to be a positive correlation between study year and the increased average BDI scores means depression chances [14].

Our study found that the prevalence of depression $40.6 \%$ which is quite nearby to the prevalence found in the Hong Kong study, which was research on Depression, anxiety, and symptoms of stress among baccalaureate nursing students in Hong Kong, a cross-sectional study found that the prevalence of mild to severe depression found to be $35.8 \%$. In which depression was found to be significantly associated with the; clinical specialty; year of study; financial difficulties; lifestyle factors including an entertainment, hobbies, relationship crises with family and peers; and quiet time; sleep problems; lack of balanced diet, exercise; and selfperceived physical and mental health [15].

\section{Conclusion and Recommendation}

\subsection{Conclusion}

The study found that the overall prevalence of depression level from mild to extremely severe were the ones suffering from depression. Of the total students, $40.6 \%$ of students were suffering from mild to the extremely severe level of depression. Confidant, interest in the field of study and age were found to have a significant association with depression. The current study showed depression having a statistically significant association with ethnicity and faculty of study. The study illustrates the substantially high prevalence of depression among university students, which is an alarming 
rate and revealing a neglected area of the students' psychology.

The high rates of depression among university students resulting in high psychological morbidity will not only have adverse effects on students' health, development, career, and quality of life but also will deteriorate influence on their own families, institutions, peers and even on other people's lives. Students are the future that shapes a nation, and whether a developed or developing country, a traditional or a modern country, no community is immune against this disorder.

The higher rates of depression warrant strategic planning focusing on interventions like social and psychological support. In a developing country like Nepal, mental health issues remain hidden, and these fields of studies are those that create extreme academic stress among students. Students have less time for refreshment and need to concentrate on academic success. Thus, the increasing rate of depression among university students is required to be addressed as soon as possible.

\subsection{Recommendations}

Based on findings from the study, the following are the recommendations:

1) Management and education are courses where students face stressors due to academic pressure. The study showed a significant association between depression and the faculty of study. An institutional-based antimental distress policy is to be formulated by respective institutions along with the establishment of a council to address the mental health issues.

2) Interest in the field of study was found to have a significant association with depression. Parents should let their children choose their field of study and create an environment of support rather than fear. Children also need to persuade their parents if their field of study does not cover their area of interest.

3) Age was also one of the factors for the causes of depression in this study. Parents need to keep in touch with their children and continuously support them, so their relationship strengthens.

4) The higher rates of depression among students warrant the need for strategic planning not only for institutions but also for the nation as students are the future of tomorrow's nation. The difference needs to be further explored for the development of better intervention programs and appropriate social and psychosocial services targeting this group.

\section{References}

[1] WHO | Depression. WHO [Internet]. 2018 [cited 2018 Mar 29]; $\quad$ Available from: http://www.who.int/mediacentre/factsheets/fs369/en/
[2] WHO | Depression. WHO [Internet]. 2017 [cited 2018 Mar 29]; Available from: http://www.who.int/mental_health/management/depression/en/

[3] Sarokhani D, Delpisheh A, Veisani Y, Sarokhani MT, Manesh RE, Sayehmiri K. Prevalence of depression among university students: A systematic review and meta-analysis study. Depress Res Treat. 2013; 2013.

[4] WHO | Mental health: strengthening our response. WHO [Internet]. 2018 [cited 2018 Mar 29]; Available from: http://www.who.int/mediacentre/factsheets/fs220/en/

[5] Ahmed HU, Hossain MD, Aftab A, Soron TR, Alam MT, Uddin A. Suicide and depression in the World Health Organization South-East Asia Region : a systematic review. 2017; 6 (April).

[6] Kunwar D, Risal A, Koirala S. Study of Depression, Anxiety and Stress among the Medical Students in two Medical Colleges of Nepal. Kathmandu Univ Med J (KUMJ) [Internet]. 2016; 14 (53): 22-6. Available from: http://www.ncbi.nlm.nih.gov/pubmed/27892436

[7] Inam SN, Saqib A, Alam E. Prevalence of anxiety and depression among medical students of private university. J Pak Med Assoc. 2003; 53 (2): 44-7.

[8] Risal A, Manandhar K, Linde M, Steiner TJ, Holen A. Anxiety and depression in Nepal: Prevalence, comorbidity and associations. BMC Psychiatry [Internet]. 2016; 16 (1): 1-9. Available from: http://dx.doi.org/10.1186/s12888-016-0810-0

[9] Sokratous S, Merkouris A, Middleton N, Karanikola M. The prevalence and socio-demographic correlates of depressive symptoms among Cypriot university students: A crosssectional descriptive co-relational study. BMC Psychiatry. 2014; 14 (1): 1-15.

[10] Adhikari A, Dutta A, Sapkota S, Chapagain A, Aryal A, Pradhan A. Prevalence of poor mental health among medical students in Nepal: A cross-sectional study. BMC Med Educ. 2017; 17 (1): 1-7.

[11] Yang G, Sau C, Lai W, Cichon J, Li W. Prevalence of Depression, Depressive Symptoms, and Suicidal Ideation Among Medical Students. 2015; 344 (6188): 1173-8.

[12] Carneiro EB, Braga RT, Silva LFD, Nogueria MC. Prevalence of Anxiety and Depression among Medical Students. Rev Bras Educ Med [Internet]. 2014; 36 (4): 524-30. Available from: http://www.scielo.br/pdf/rbem/v39n3/1981-5271-rbem-39-30388.pdf

[13] Teh CK, Ngo CW, Aniyah R, Vellasamy R, Suresh K. Depression, Anxiety and Stress among Undergraduate Students: A Cross Sectional Study Choon. Open J Epidemioogy. 2015; 5 (November): 260-8.

[14] Bostanci M, Ozdel O, Oguzhanoglu NK, Ozdel L, Ergin A, Ergin N, et al. Depressive symptomatology among university students in Denizli, Turkey: prevalence and sociodemographic correlates. Croat Med J. 2005; 46 (1): 96-100.

[15] Cheung T, Wong SY, Wong KY, Law LY, Ng K, Tong MT, et al. Depression, anxiety and symptoms of stress among baccalaureate nursing students in Hong Kong: A crosssectional study. Int J Environ Res Public Health. 2016; 13 (8). 